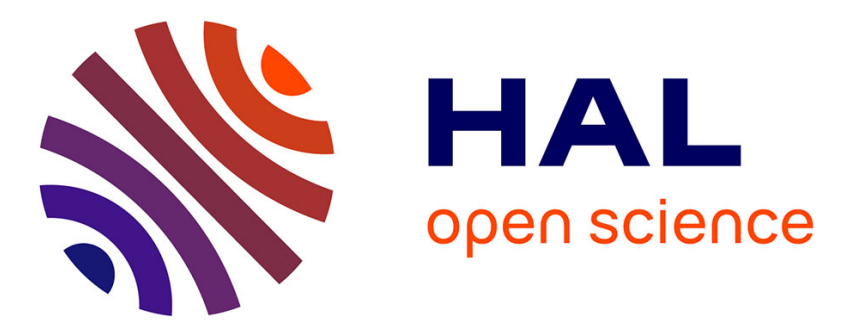

\title{
In vitro cyclic fatigue and hydrothermal aging lifetime assessment of yttria-stabilized zirconia dental ceramics
}

C. Wei, X. Gong, C. Xie, Z.X. Chen, S.B. Li, Laurent Gremillard

\section{To cite this version:}

C. Wei, X. Gong, C. Xie, Z.X. Chen, S.B. Li, et al.. In vitro cyclic fatigue and hydrothermal aging lifetime assessment of yttria-stabilized zirconia dental ceramics. Journal of the European Ceramic Society, 2020, 40 (13), pp.4647-4654. 10.1016/j.jeurceramsoc.2020.04.016 . hal-02877853

\section{HAL Id: hal-02877853 https://hal.science/hal-02877853}

Submitted on 22 Jun 2020

HAL is a multi-disciplinary open access archive for the deposit and dissemination of scientific research documents, whether they are published or not. The documents may come from teaching and research institutions in France or abroad, or from public or private research centers.
L'archive ouverte pluridisciplinaire HAL, est destinée au dépôt et à la diffusion de documents scientifiques de niveau recherche, publiés ou non, émanant des établissements d'enseignement et de recherche français ou étrangers, des laboratoires publics ou privés. 


\title{
IN VITRO CYCLIC FATIGUE AND HYDROTHERMAL AGING LIFETIME ASSESSMENT OF YTTRIA-STABILIZED ZIRCONIA DENTAL CERAMICS
}

\author{
Published in Journal of the European Ceramic Society (2020), 40 (13) pp. 4645-54 \\ https://doi.org/10.1016/j.jeurceramsoc.2020.04.016
}

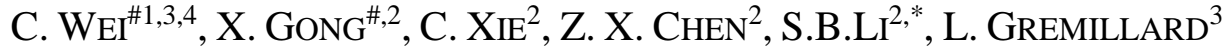

${ }^{1}$ School of Mechanics, Civil Engineering and Architecture, Northwestern Polytechnical University, Xi'an 710072, P. R. China

${ }^{2}$ State Key Laboratory of Military Stomatology, Department of Dental Materials, School of Stomatology, Fourth Military Medical University, Xi'an, Shaanxi, China 710032

${ }^{3}$ Univ. Lyon, INSA-Lyon, CNRS, MATEIS, UMR 5510, F-69100 Villeurbanne, France

${ }^{4}$ Science and Technology on Thermostructural Composite Materials Laboratory, Northwestern Polytechnical University, Xi'an, 710072, P. R. China
\end{abstract}

Author Contributions

${ }^{\#}$ C. W. and X. G. contributed equally.

* Corresponding author: S.B.Li, lishibao@fmmu.edu.cn

\begin{abstract}
The in vitro lifetime assessment of dental zirconia has been the focus of the researchers in the development of dental zirconia applications. This work mainly studied the cyclic fatigue lifetime in saliva and aging lifetime of three commercial zirconia dental materials: two kinds of $3 \mathrm{~mol} \%$-yttria partially stabilized zirconia ST (super translucence) and MT(medium translucence), in which MT contains a small amount of alumina; and a $5 \mathrm{~mol} \%$ yttria stabilized zirconia TT (tooth translucency). ST and MT materials have higher initial mechanical strength (flexural strength) and initial crack propagation threshold than TT materials and thus have longer cycle fatigue lifetime, but TT has the best aging resistance (no aging) in existing aging procedures. MT has a higher average initial mechanical strength and better aging resistance than the ST samples due to the influence of alumina at the grain boundary, but has lower strength reliability. Finally, the service lifetime of the three materials was evaluated, and some guidance for their use and design is provided by combining the analysis of the collected dental zirconia restorations.
\end{abstract}

\section{KEYWORDS}

zirconia; aging; cycle fatigue 


\section{INTRODUCTION}

With the development of aesthetic properties and manufacturing technology of dental zirconia ceramics, they are widely used in dental restorations in the last decade[1-7]. However, the failures of zirconia restorations may be induced by inappropriate design and manufacturing, improper preparation of abutment teeth, low fatigue performance and unique hydrothermal aging behaviour of zirconia ceramics[1, 4, 8-13]. The influence of the previous two factors on the lifetime of zirconia restorations has been widely discussed[4, 12-14], but the interactions of the last two factors is less known. Therefore, systematically assessing the effects of long-term fatigue behaviour and hydrothermal aging behaviour on the service lifetime of zirconia dental devices is a necessary task for the continued development of zirconia dental application $[15,16]$.

Due to the subcritical crack growth (SCG) behavior of zirconia ceramics, their failures tend to occur at loads well below the initial strength[17, 18]. In particular, if radial cracks appear on the surface, SCG may reduce the load bearing capacity of the zirconia restoration over time[19]. In addition, due to the role of water molecules in SCG, the crack propagation velocity is also accelerated in the wet environment of the human mouth, which leads to the bulk fractures[20]. Therefore, for cyclic fatigue lifetime of zirconia, the subcritical crack growth (SCG) curves of zirconia are pointed to play a decisive role. These SCG curve can be obtained indirectly through dynamic fatigue[1, 21, 22].

Hydrothermal aging, also called low temperature degradation, is a spontaneous phase change of zirconia under water or humid environment. It can be described as follows: the presence of water in the environment of zirconia pieces triggers the tetragonal to monoclinic $(\mathrm{t}-\mathrm{m})$ transformation of some grains on the surface, which potentially leads to roughening and micro-cracking because of the volume increase $(\sim 5 \%)$ associated to the t-m transformation[23]. Hydrothermal aging is driven by the annihilation of oxygen vacancies by water-derived species[24]. Many factors such as different grain size, residual or applied stresses, density, content of $\mathrm{Y}_{2} \mathrm{O}_{3}$ in tetragonal phase, proportion of cubic phase, doping with more than one oxide, surface treatments, all contribute towards the aging process [8, 25-32]. In particular, zirconia ceramics doped with different contents of yttria show very different resistance to ageing, both through the intrinsic stability of the tetragonal phase (more stable as the $\mathrm{Y}$ content increases) and through the different sensitivities to applied or residual stresses (for example, $4 \mathrm{~mol} \%$ yttria stabilized tetragonal zirconia (4Y-TZP) is more sensitive than 3Y-TZP to residual stresses due to polishing process[28]). In order to study the hydrothermal aging process of zirconiabased ceramics more quickly and conveniently, a fast and stepwise procedure was used to predict the aging lifetime of zirconia[27, 33]. And some studies have shown that aging impaired the mechanical properties of dental zirconia[34, 35].

Although many studies have been conducted on the lifetime evaluation of dental zirconia in vitro, most of them only focus on the assessment of fatigue lifetime[1, 20,21]. The aim of the present study is to investigate the service lifetime (not equivalent to clinical lifetime) of three commercial zirconia dental ceramics submitted to both ageing and fatigue, i.e. to conditions that are deemed more representative of the real-life conditions. 


\section{MATERIALS AND METHODS}

\subsection{MATERIAL PREPARATION}

Three different commercial zirconia materials (Upcera, Co. Ltd, Shenzhen, China) were studied:

-One conventional full-strength 3Y-TZP grade that is commonly used in clinical practice (ST- super translucence group),

-One with improved strength $3 \mathrm{Y}$-TZP grade that contain about $0.5 \mathrm{wt} \%$ alumina (MT-medium translucence group),

-One highly translucent and partially cubic Y-TZP grade (TT-tooth translucency group).

Here, the transmittances of ST, MT, and TT provided by the suppliers are $43 \%, 39 \%, 49 \%$ respectively when the thickness of sintered samples is $1 \pm 0.02 \mathrm{~mm}$.

All the materials were provided in the form of commercial pre-sintered $98 \mathrm{~mm}$ disks. And all designed bodies were processed by CAD-CAM technology from the pre-sintered disks. Considering the volume shrinkage after sintering, all materials were shaped as $63.3 \times 25.3 \times 2.6 \mathrm{~mm}$ plates for hardness tests (at least 2 per material), $30 \times 5.3 \times 1.7 \mathrm{~mm}$ plates for bending tests ( 15 per material) and fatigue tests (at least 5 per material), $12.7 \times 12.7 \times 2.6 \mathrm{~mm}$ plates for aging tests (at least 2 per material). Then the bodies were sintered in a programmable furnace (firstly heating at $10^{\circ} \mathrm{C} / \mathrm{min}$ to $1000^{\circ} \mathrm{C}$ and then heating at $4^{\circ} \mathrm{C} / \mathrm{min}$ to a dwell at $1480^{\circ} \mathrm{C}$ for $2 \mathrm{~h}$, and finally cooling down to room temperature at $5^{\circ} \mathrm{C} / \mathrm{min}$ ). Then the sintered samples were polished for every sample. And the polished samples of $50 \times 20 \times 2 \mathrm{~mm}$ were prepared for hardness tests, the samples of $25 \times 4 \times 1.2 \mathrm{~mm}$ were for bending tests, fatigue tests and the samples of $10 \times 10 \times 2 \mathrm{~mm}$ were for aging tests. Some of them were annealed to remove as much as possible machining and polishing residual stresses $\left(1250^{\circ} \mathrm{C}\right.$ for $0.5 \mathrm{~h} \mathrm{at} 5^{\circ} \mathrm{C} / \mathrm{min}$ [36]). This procedure also resulted in a light thermal etching, thus the annealed samples were used for microstructural characterization.

\subsection{Microstructure, PHASE ASSEMBLAge AND COMPOSITION}

The SEM observations for three materials were conducted after annealing using a Zeiss Supra55 VP microscope with secondary electron images and a low acceleration voltage $(2 \mathrm{kV})$ without conductive coating. And Grain sizes were obtained from the micrograph using the linear intercept method[37]. The phase assemblage and composition analysis was obtained from a large angular range (15-120 deg. 2 $\theta$ ) XRD patterns(using a D8 Advance diffractometer, Bruker, Germany, with step size 0.02 deg and scan speed $1 \mathrm{~s} / \mathrm{step}$ ), using a procedure detailed in ref [27]. Here the content of $\mathrm{Y}_{2} \mathrm{O}_{3}$ in the cubic and tetragonal phases were deduced from the lattice parameters (determined by Rietveld Refinement using the Topas 4.0 software) and compared to a calibration curve established from PDF files and previous work by Scott [38-40].

\subsection{HARDNESS ANALYSIS AND CRACK PROPAGATION THRESHOLD}

Hardness tests were performed on polished plates using a Vickers hardness tester (Future-tech Testwell HV700) with a $20 \mathrm{~kg}$ load and a $10 \mathrm{~s}$ dwell time (at least 20 indents per material). The threshold for crack propagation $\left(\mathrm{K}_{\mathrm{I}}\right)$ was evaluated from the radial crack pattern accompanying the same 20 Vickers indentations (measured at least $72 \mathrm{~h}$ after indentation so that the radial cracks reached a stable shape and length) and calculated according to Anstis' equation[41]. This measure of the crack propagation threshold is based on the fact that zirconia is sensitive to subcritical crack propagation; thus cracks created at the indent corner propagate until $\mathrm{K}_{\mathrm{I}}$ reaches the threshold value $\left(\mathrm{K}_{\mathrm{I} 0}\right)$ under the influences of the humidity present in atmosphere and of the residual stresses around the Vickers indent. In these conditions Anstis' equation does not give access to $\mathrm{K}_{\mathrm{IC}}$, but to $\mathrm{K}_{\mathrm{IO}}$ [42]. 


\subsection{FLEXURAL StRENGth}

Flexural strength was measured by three-point bending on specimens (beams)placed in artificial saliva at $37{ }^{\circ} \mathrm{C}$, using a testing machine (MUF-1050, CARE-Mesurement \& Control, Co. Ltd, Shenzhen, China). These measurements were carried out using a crosshead speed of $0.5 \mathrm{~mm} / \mathrm{min}$ and a span of $20 \mathrm{~mm}$ between the rollers. Failure loads were recorded and the flexural strength values were calculated according to the ISO 6872:2015 standard.

\subsection{AsseSSMENT OF CYCLIC FATIGUE}

The number of failure cycles $\mathrm{N}_{\mathrm{f}}$ for three materials in artificial saliva were measured by using the same machine (MUF-1050). In order to complete the test quickly, the sinusoidal cyclic loading was applied to the ceramic specimens at a frequency of $10 \mathrm{~Hz}$ with a constant maximum load level of $158 \mathrm{~N}$ for ST, $160 \mathrm{~N}$ for MT and $73 \mathrm{~N}$ for TT specimens. These maximum load values are equivalent to applied stress values of $686 \mathrm{MPa}, 691 \mathrm{MPa}$ and $318 \mathrm{MPa}\left(\sigma_{\max }\right)$ for the ST, MT and TT samples, respectively, which correspond to approximately $60 \%$ of the average flexural strength of the specimens measured in static conditions (2.4).

However, the maximum applied stress during the chewing process is usually much smaller than $60 \%$ of the average flexural strength of the specimens, which is about $150 \mathrm{MPa}[1]$. Here the fatigue lifetime $\left(\mathrm{N}_{\mathrm{f}}\right)$ at different applied maximum stress $\left(\sigma_{\max }\right)$ during loading and the mechanical properties can be related by the following equation $[1,20]$ :

$N_{f}=\frac{2 K_{I C}^{2-n} \sigma_{0.05}^{n-2}}{A Y^{2}(\mathrm{n}-2)\left(\sigma_{\max }\right)^{n}}$

Where $\mathrm{N}_{\mathrm{f}}$ is the number of cycles to failure for the specimen, $\mathrm{K}_{\mathrm{IC}}$ is the critical stress intensity factors (here $\mathrm{K}_{\mathrm{IC}}$ of ST and MT is $5 \mathrm{MPa} . \mathrm{m}^{1 / 2}$, TT is $3.2 \mathrm{MPa}^{1 / 2}$, data provided by suppliers), $\sigma_{0.05}$ is the mechanical strength values corresponding to a failure probability of $5 \%$ in Weibull statistics, $\sigma_{\max }$ is the maximum stress applied during loading, $\mathrm{n}$ and A are the SCG parameters under cyclic loading, $\mathrm{Y}$ is a geometrical constant that depends on crack location and shape (equal to 1.3 for surface cracks). Therefore these two parameters $\mathrm{n}$ and $\mathrm{A}$ are what we need to obtain and are used to derive the fatigue lifetime of the material.They can be calculated from the Weibull distributions or from the empirical law of Paris (crack propagation velocity vs $\mathrm{K}_{\mathrm{I}, \max }$ equation). The derivation processes are as follows.

The initial mechanical strength data (flexural strength, $\sigma$ ) and the number of failure cycles data $\left(\mathrm{N}_{f}\right)$ were described by Weibull statistics, using the following equations [43, 44], meanwhile these results are used to simulate confidence intervals (95\% confidence levels) by software Origin pro9.

$$
\begin{aligned}
& \ln \left[\ln \left(\frac{1}{1-F_{i}}\right)\right]=m \cdot \ln (\sigma)-m \cdot \ln \left(\sigma_{0}\right) \\
& \ln \left[\ln \left(\frac{1}{1-F_{j}}\right)\right]=m^{*} \cdot \ln \left(\mathrm{N}_{f}\right)-m^{*} \cdot \ln \left(\mathrm{N}_{f 0}\right)
\end{aligned}
$$

Where $F_{i}$ and $F_{j}$ are the probabilities of failure. $\sigma$ is the initial mechanical strength. $N_{f}$ is the number of cycles until failure. $\sigma_{0}$ and $\mathrm{N}_{\mathrm{f} 0}$ are the characteristic mechanical strength and the characteristic number of cycles at a failure probability of $63.21 \% . \mathrm{m}, \mathrm{m}^{*}$ are the Weibull moduli. The failure probability was calculated assuming the following relation: $F_{i}=(i-0.5) / N$, where $F_{i}$ is the failure probability of the " $\mathrm{i}$ "th specimen (in a strength-increasing rank, $\sigma_{\mathrm{i}}$ ) and $\mathrm{N}$ is the total number of specimens tested. $F_{j}$ is calculated using the same method. Finally, $n$ and $A$ in the equation (1) can be calculated by following the relationship below according to the results of the Weibull distribution parameters[45]: 
$n=\frac{m}{m^{*}}+2$

$A=\frac{2 K_{I C}^{(2-n)} \sigma_{0}^{(n-2)}}{N_{f 0} Y^{2}(n-2)\left(\sigma_{\max }\right)^{n}}$

The subcritical crack growth (SCG) curves can be derived from the mechanical strength and fatigue lifetime data. Through ranking the strength $(\sigma)$ and lifetime $\left(\mathrm{N}_{\mathrm{f}}\right)$ data in an increasing order, the crack velocity $\mathrm{v}$ and the corresponding stress intensity factor $\mathrm{K}_{\mathrm{I}, \mathrm{max}}$ follow the equations below:

$\mathrm{K}_{I, \max }=\frac{K_{I C} \sigma_{\max }}{\sigma}$

$v=\frac{2 p\left(K_{I C}\right)^{2}}{N_{f} \sigma^{2} Y^{2}}$

Where $p$ is the slope of a linear fitting to the data which is the form of $\log \left(\sigma_{\max } / \sigma\right)$ as a function of $\log \left(\mathrm{N}_{\mathrm{f}} \cdot \sigma_{\max }{ }^{2}\right)$.

Finally, the parameters $\mathrm{n}$ and $\mathrm{A}$ in the equation (1) can be evaluated by the empirical law of Paris[44, 46]:

$v=A \Delta K_{I}^{n}=A(1-R)^{n} K_{I, \max }^{n}=A^{*} K_{I, \text { max }}^{n}$

Where $\Delta K_{\mathrm{I}}$ is the amplitude of the applied stress intensity factor $\left(K_{\mathrm{I}, \max }-K_{\mathrm{I}, \min }\right), K_{\mathrm{I}, \max }$ and $K_{\mathrm{I}, \min }$ are the applied maximum and minimum stress intensity factors, $R$ is the ratio $K_{\mathrm{I}, \mathrm{min}} / K_{\mathrm{I}, \mathrm{max}}$. The applied cyclic stress varied between 0 and $\sigma_{\max }$ in this study; thus $\sigma_{\min }=K_{\operatorname{Imin}}=R=0, \Delta \sigma=\sigma_{\max }$, $\Delta K_{\mathrm{I}}=K_{\mathrm{I}, \max }$ and $A=A^{*}$.

\subsection{AsSESSMENT OF AGING KINETICS}

The monoclinic phase content was calculated from X-ray diffraction using a D8 advance Diffractometer (Bruker, Germany) with $\mathrm{K} \alpha$ radiations, in Bragg-Brentano configuration. XRD patterns were recorded in the $27-33^{\circ}(2 \theta)$ range with a scan speed of $0.2 \mathrm{~min}^{-1}$ and a step size of $0.05^{\circ}$. The monoclinic $\mathrm{ZrO}_{2}$ phase content $\left(V_{m}\right)$ was expressed after Toraya's equation[47]:

$V_{m}=\frac{1.311 X_{m}}{1+0.311 X_{m}}$

In which the value of $X_{m}$ was calculated using Garvie and Nicholson method:

$X_{m}=\frac{I_{m}^{-111}+I_{m}^{111}}{I_{m}^{-111}+I_{m}^{111}+I^{101}}$

Where $I_{p}^{h k l}$ is the area of the diffraction peak related to the $(h k l)$ plane of phase $p$ ( $m$ for monoclinic and $t$ for tetragonal).

The hydrothermal ageing kinetics are rationalized by fitting the transformation curves with the MehlAvrami-Johnson laws[48].

$f=\frac{V_{m}-V_{0}}{V_{\max }-V_{0}}=1-\exp \left(-(b t)^{n}\right), b=b_{0} \exp \left(-\frac{Q}{R T}\right)$

where $\mathrm{V}_{\mathrm{m}}$ is the monoclinic phase content after a given time $t, \mathrm{~V}_{\max }$ and $\mathrm{V}_{0}$ are the saturation and initial levels of monoclinic phase content. Over a range covering at least 20 to $150^{\circ} \mathrm{C}, b$ is thermally activated ( $Q$ being the activation energy, $R$ the gas constant, and $T$ the absolute temperature).

Combining these equations and the fact that ageing is cumulative led to the stepwise ageing procedure used here, and that takes advantage of the following equation to evaluate the aging kinetics of zirconia [27] (for detailed process, see reference[33]): 
$\ln \left[\frac{1}{\Delta t_{i}} \ln \left(\frac{V_{\max }-V_{i-1}}{V_{\max }-V_{i}}\right)\right] \approx \ln \left(n b_{0}\right)-\frac{Q}{R T_{i}}$

For each material, the $\mathrm{V}_{\max }$ value can be obtained by phase analysis, and $\mathrm{Q}$ value can be obtained by Equation 12. Other parameters can be obtained by using equation (11) and the fitting procedure which consists in minimizing the total quadratic error by optimizing an identical set of parameters $\left(b_{0}, n\right)$ for the kinetics measured at all temperatures[27]. The time/temperature schedules used for the stepwise procedure here are shown in Table 1.

Table 1 : Aging procedure for all materials

\begin{tabular}{cccccc}
\hline \multicolumn{2}{c}{ Schedule1: $\mathrm{ST}$} & \multicolumn{2}{c}{ Schedule 2: MT } & \multicolumn{2}{c}{ Schedule3:TT } \\
\hline $\mathrm{T}_{\mathrm{i}}\left({ }^{\circ} \mathrm{C}\right)$ & $\Delta \mathrm{t}_{\mathrm{i}}(\mathrm{h})$ & $\mathrm{T}_{\mathrm{i}}\left({ }^{\circ} \mathrm{C}\right)$ & $\Delta \mathrm{t}_{\mathrm{i}}(\mathrm{h})$ & $\mathrm{T}_{\mathrm{i}}\left({ }^{\circ} \mathrm{C}\right)$ & $\mathrm{t}_{\mathrm{i}}(\mathrm{h})$ \\
\hline 134 & $2+2$ & 134 & $2+2$ & 134 & 200 \\
121 & $6+6$ & 121 & $6+6+6$ & 90 & 1720 \\
111 & $10+5$ & 111 & $10+20+6$ & & \\
100 & $22+6+8$ & 100 & $60+22+20$ & & \\
90 & 50 & 134 & $2+8+3$ & & \\
& & 90 & 100 & & \\
\hline
\end{tabular}

\section{RESULTS AND DISCUSSIONS}

\subsection{MicRostructure}

Microstructures of all the materials (observed by SEM) are shown in Fig. 1. The MT sample contains a small amount of alumina (black grain in SEM photo) compared to the ST and TT samples. The phase content and phase partitioning, analyzed by X-ray diffraction coupled to Rietveld analysis, are summarized in Table 2. The TT sample has larger cubic phase content (about 59\%) and a larger grain size due to more yttrium oxide content. And the tetragonal phase content for ST sample is $78 \%$, and for MT is $79 \%$.

Table 2: Microstructural features of zirconia materials before aging.

\begin{tabular}{lllllll}
\hline Material & $\begin{array}{l}\mathrm{Y}_{2} \mathrm{O}_{3} \\
\text { content } \\
(\mathrm{mol} . \%)\end{array}$ & $\begin{array}{l}\text { \% cubic } \\
\pm 0.5\end{array}$ & $\begin{array}{l}\text { \% tetragonal } \\
\pm 0.5\end{array}$ & $\begin{array}{l}\mathrm{mol} \% \\
\mathrm{Y}_{2} \mathrm{O}_{3} \text { in c } \\
\pm 0.05\end{array}$ & $\begin{array}{l}\text { mol\% } \\
\mathrm{Y}_{2} \mathrm{O}_{3} \text { in } \mathrm{t} \\
\pm 0.05\end{array}$ & $\begin{array}{l}\text { Grain } \\
\text { size(nm) } \\
\pm 10\end{array}$ \\
\hline ST & 3 & 22.3 & 77.6 & 6.64 & 2.62 & 420 \\
MT & 3 & 20.9 & 79.1 & 6.42 & 2.5 & 490 \\
TT & 5 & 58.6 & 41.4 & 6.00 & 3.64 & 930 \\
\hline
\end{tabular}



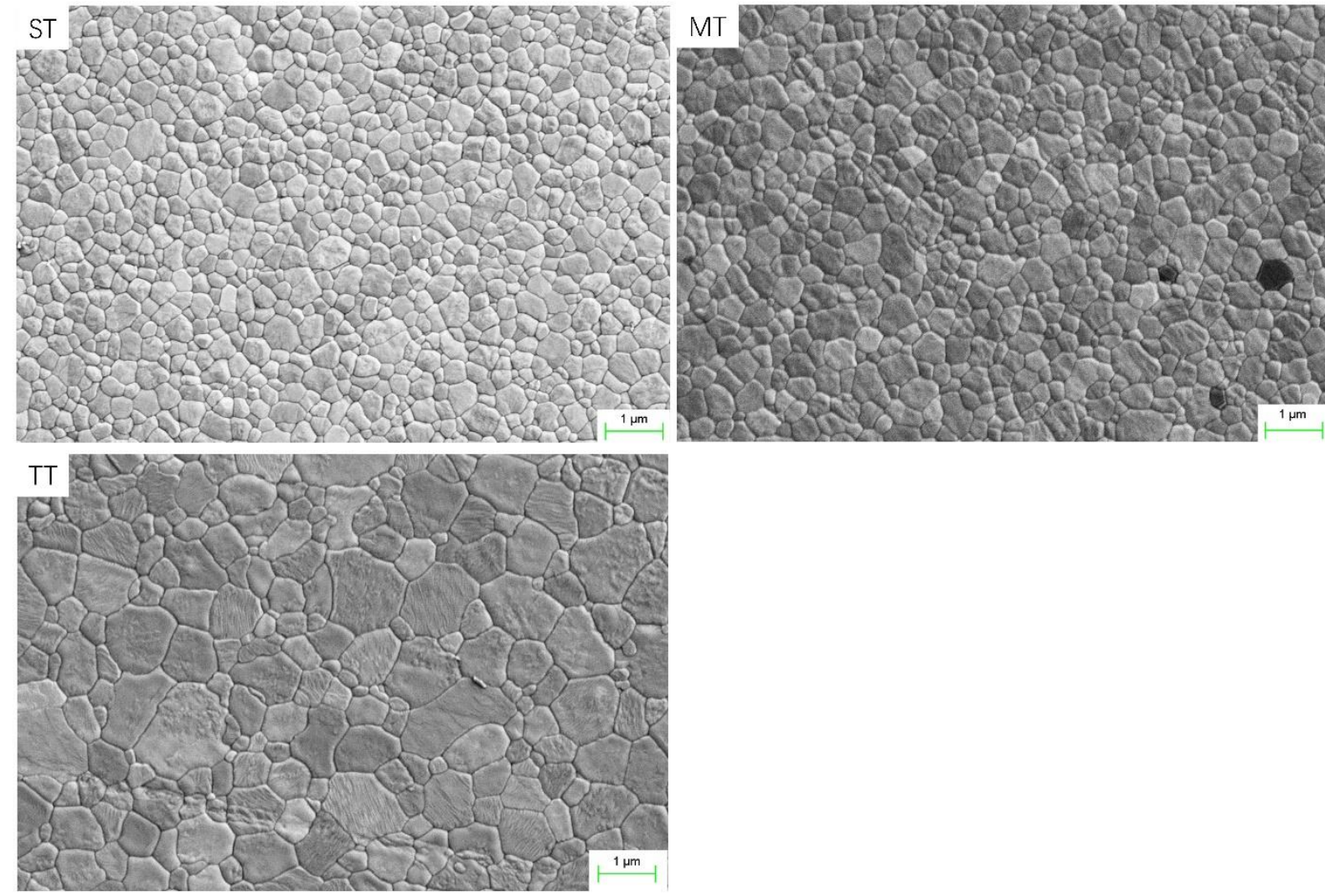

Figure 1: SEM micrographs of all annealed samples

\subsection{VICKERS HARDNESS AND CRACK PROPAGATION THRESHOLD}

Fig.2 summarizes that the Vickers hardness and crack propagation threshold $\left(\mathrm{K}_{\mathrm{I}}\right)$ of each material. Vickers hardness were around $13.0 \mathrm{GPa}$ for all samples. The crack propagation thresholds $\left(\mathrm{K}_{\mathrm{I} 0}\right)$ of ST and MT samples (3.26 and 3.9 MPa.m ${ }^{1 / 2}$ respectively) are higher than that of TT (around 2.67 MPa.m ${ }^{1 / 2}$, Fig.2(b)).
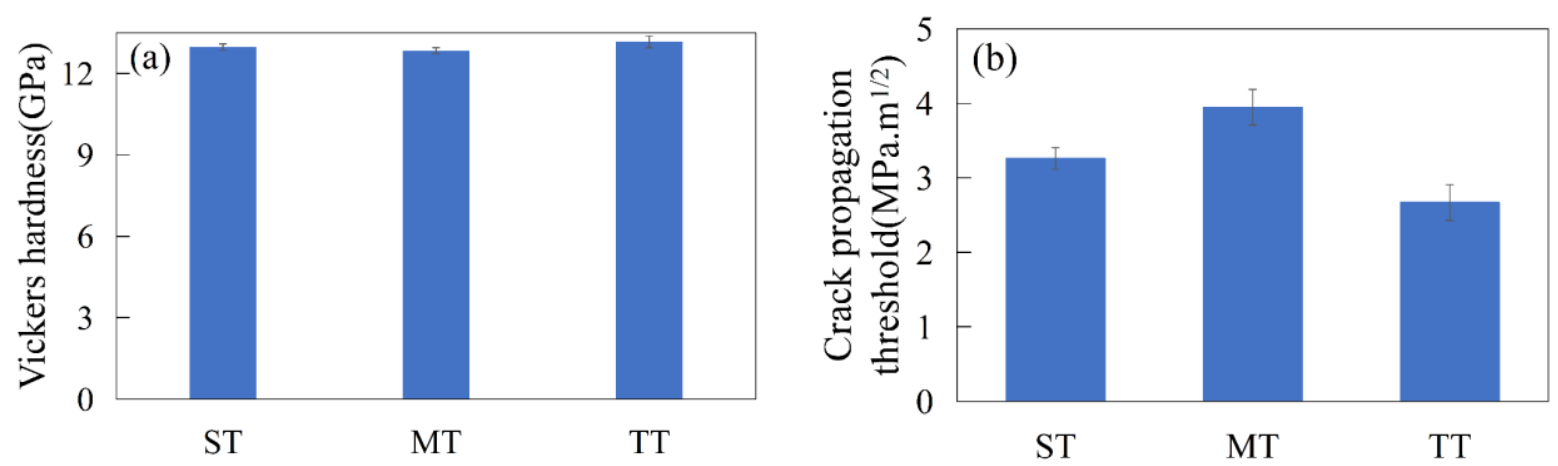

Figure 2: Vickers hardness and Crack propagation threshold for all materials

\subsection{FLEXURAL STRENGTH AND CYCLIC FATIGUE RESULTS}

Fig. 3 shows that the flexural strength for different materials. The average flexural strength of ST, MT and TT was 1143, 1152 and $530 \mathrm{MPa}$, respectively. Therefore, the applied loading stresses value $\left(\sigma_{\max }\right)$ used in the cyclic fatigue test in this study is approximately $60 \%$ of the average flexural strength: $686 \mathrm{MPa}, 691 \mathrm{MPa}$ and $318 \mathrm{MPa}$ for the ST, MT and TT samples, respectively. Fig.4 describes the Weibull plots with $95 \%$ confidence bands for initial mechanical properties (flexural strength) and 
fatigue lifetime (the statistical parameters obtained from the Weibull distributions are summarized in table 3). These parameters are used to evaluate the parameters $A$ and $n$ in the fatigue lifetime prediction equation (1). For the strength, MT has an lower Weibull modulus than ST and TT in Fig.4(a). However for the fatigue lifetime in Fig.4(b), the Weibull modulus $\mathrm{m}^{*}$ of MT is 0.51, higher than ST and TT.

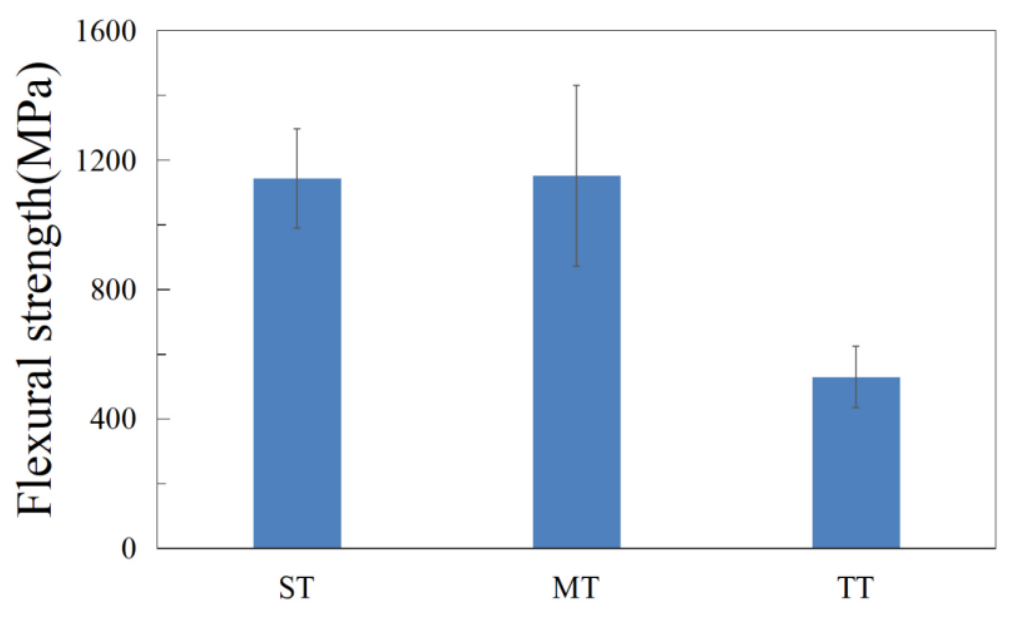

Figure 3: Flexural strength from bending tests for all samples

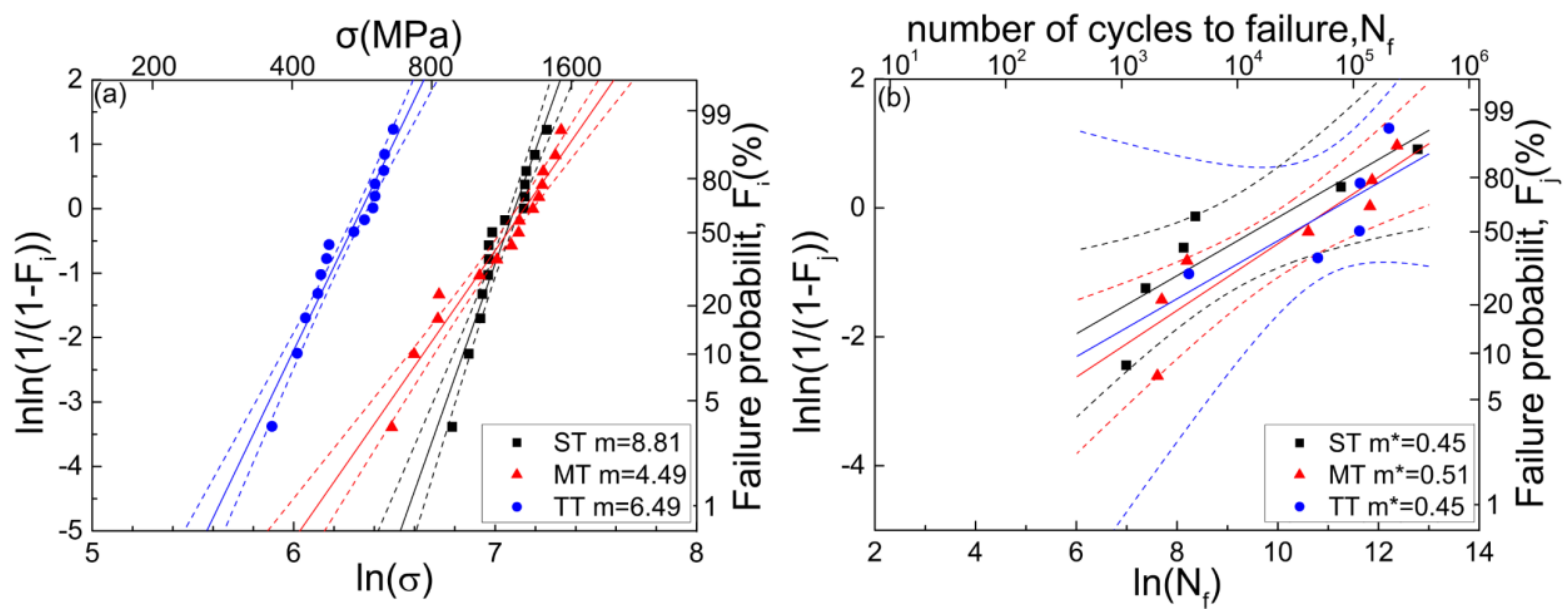

Figure 4: Weibull plots for the initial mechanical strength (flexural strength) and fatigue lifetime with $95 \%$ confidence bands of the specimens

Table 3: Statistical parameters obtained from the Weibull distributions of the initial mechanical strength and fatigue lifetime

\begin{tabular}{lllllll}
\hline Material & \multicolumn{3}{c}{ Bending tests } & \multicolumn{3}{c}{ Cyclic fatigue tests } \\
\cline { 2 - 7 } & $\mathrm{m}$ & $\sigma_{0}$ & $\sigma_{0.05}$ & $\mathrm{~m}^{*}$ & $\mathrm{~N}_{\mathrm{f} 0}$ & $\sigma_{\max }(\mathrm{MPa})$ \\
\hline ST & 8.81 & 1207 & 864 & 0.45 & 30710 & 686 \\
MT & 4.49 & 1263 & 657 & 0.51 & 64150 & 691 \\
TT & 6.49 & 568 & 360 & 0.45 & 69862 & 318 \\
\hline
\end{tabular}

In order to obtain the parameters of the SCG curve from the strength and the fatigue lifetime data according to Equation (6) and (7), the strength data corresponding to the fatigue lifetime data is composed of the average of every three strength value of the ranked raw flexural strength data. The 
parameter $\mathrm{p}$ in Equation (7) for different materials is described in Fig.5. And the SCG curves calculated by the above method for all materials are shown in Fig.6. The $v$-K $\mathrm{K}_{\mathrm{I}, \mathrm{max}}$ curves for ST and MT samples are nearly identical, and their $\mathrm{K}_{\mathrm{I} \text {,max }}$ values are much larger than the TT samples at the same rate of crack growth due mainly to their different critical stress intensity factors caused by different yttria content. In materials with high $\mathrm{K}_{\mathrm{IC}}$ such as ST and MT samples, subcritical crack growth was detected only for $\mathrm{K}_{\mathrm{I} \text {,max }}$ values higher than about 2.6 and $2.4 \mathrm{MPa} \cdot \mathrm{m}^{1 / 2}$, respectively. For the TT samples, the $\mathrm{k}$ value at the onset of subcritical crack propagation is as low as $1.5 \mathrm{MPa} . \mathrm{m}^{1 / 2}$. These values are consistent with current literature[17, 18].

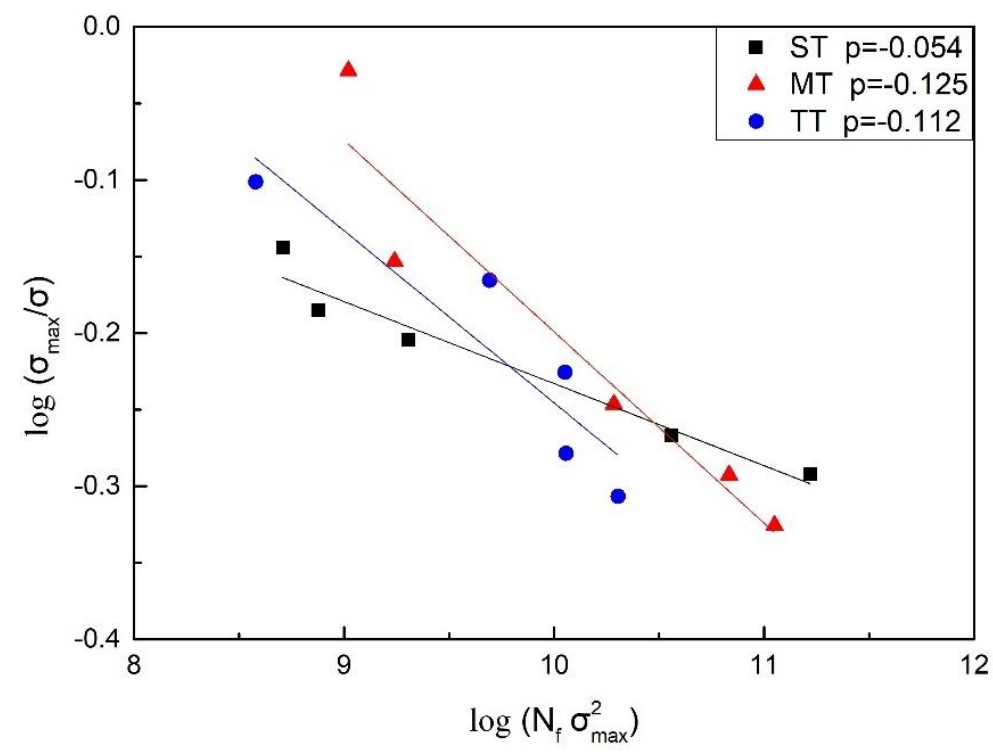

Figure 5: Auxiliary diagram used for the calculation of the subcritical crack growth curve

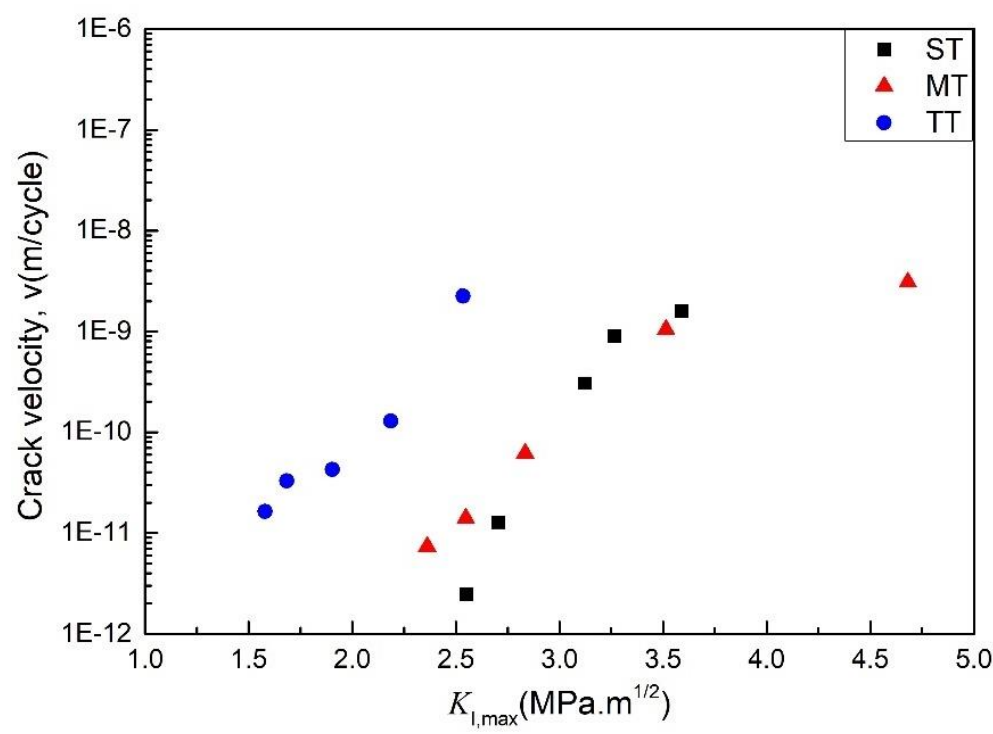

Figure 6: Crack velocity as a function of the maximum stress intensity factor applied during cyclic loading of all specimens under wet conditions. The data were calculated by using the statistical method employed in this work.

SCG parameters A and $\mathrm{n}$ are obtained by the above two methods and are summarized in Table 4 . ST samples exhibit higher a stress corrosion coefficien $(n \approx 20)$ than MT and TT samples, which resulted in the ST sample exhibiting the highest Weibull modulus in the Weibull distribution of initial strength. In addition, these parameters can be used to predict the fatigue lifetime of other different applied maximum stresses $\left(\sigma_{\max }\right)$, such as $150 \mathrm{MPa}$ during mastication[20]. 
Table 4: SCG parameters A and n from the Weibull distributions and from the subcritical crack growth curves

\begin{tabular}{lllll}
\hline Material & \multicolumn{2}{c}{$\begin{array}{c}\text { From Weibull } \\
\text { distributions }\end{array}$} & \multicolumn{2}{c}{$\begin{array}{c}\text { From subcritical crack } \\
\text { growth curves }\end{array}$} \\
\cline { 2 - 5 } & $\mathrm{A}$ & $\mathrm{n}$ & $\mathrm{A} *$ & $\mathrm{n}^{*}$ \\
\hline ST & $5.77 \cdot 10^{-21}$ & 21.54 & $3.23 \cdot 10^{-20}$ & 19.81 \\
MT & $7.13 \cdot 10^{-16}$ & 10.68 & $3.17 \cdot 10^{-15}$ & 9.32 \\
TT & $2.55 \cdot 10^{-15}$ & 16.45 & $1.63 \cdot 10^{-13}$ & 9.51 \\
\hline
\end{tabular}

\subsection{AGING KINETICS}

TT samples do not suffer from aging, even after more than $200 \mathrm{~h}$ autoclave at $134{ }^{\circ} \mathrm{C}, 1720 \mathrm{~h}$ at 90 ${ }^{\circ} \mathrm{C}$. Fig.7 shows ageing kinetics calculated according to equation (12) after the stepwise procedure. It was found that the thermal activation energy Q for aging of MT $(112 \mathrm{~kJ} / \mathrm{mol})$ is greater than ST $(98.6$ $\mathrm{kJ} / \mathrm{mol}$ ), the results are consistent with these reports [27, 48, 49]. The surface phase transformation curves for the ST and MT samples as a function of the hydrothermal ageing time are shown in Fig. 8. And the parameters of MAJ equation of the different samples were obtained using the procedure described in section 2.3, and summarized in Table 5. It was found that the aging behaviour of ST sample was more sensitive than MT sample. Here it was known that $1 \mathrm{~h}$ at $134^{\circ} \mathrm{C}$ would roughly correspond to 1 year of hydrothermal ageing in vivo for ST and 4 years for MT. These parameters are prepared to predict the aging process at $37^{\circ} \mathrm{C}$.
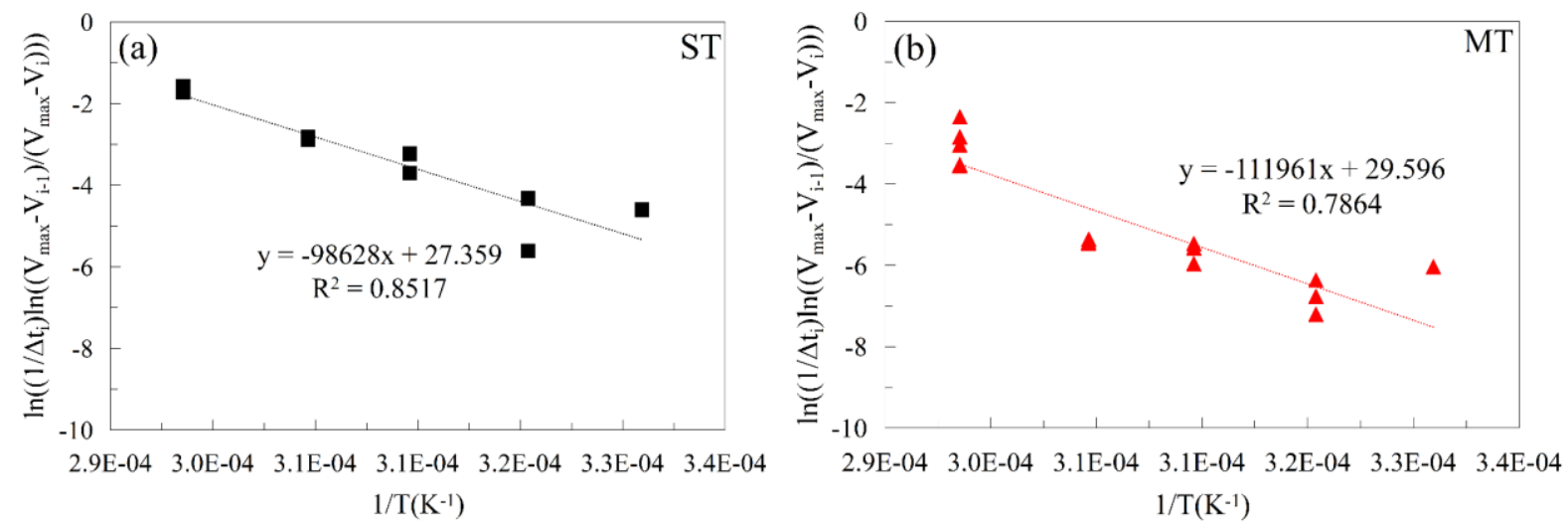

Figure 7: Ageing kinetics calculated after the stepwise procedure

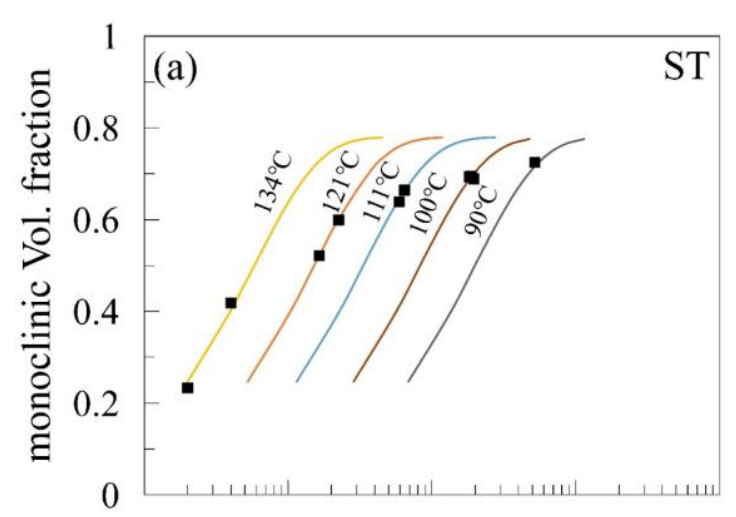

$\begin{array}{llllll}1.0 \mathrm{E}+00 & 1.0 \mathrm{E}+01 \quad 1.0 \mathrm{E}+02 \quad 1.0 \mathrm{E}+03 \quad 1.0 \mathrm{E}+04\end{array}$ aging time(h)

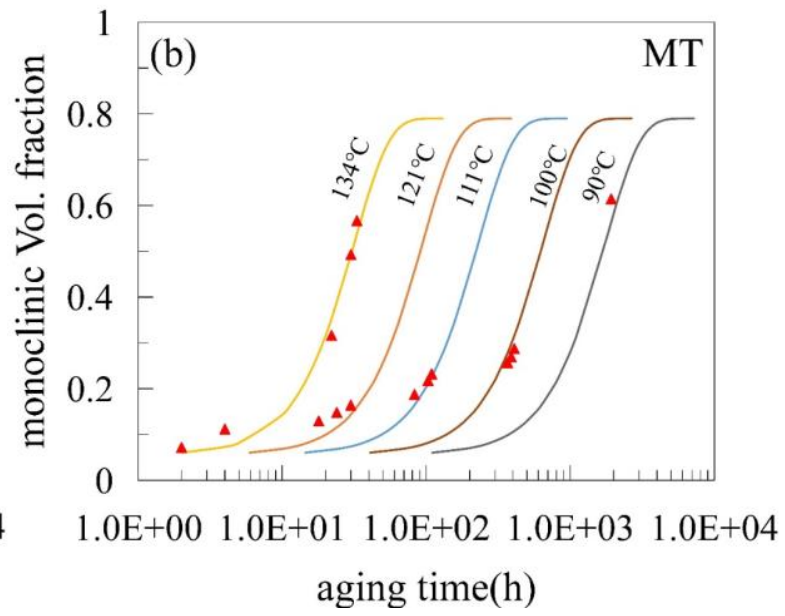

aging time(h)

Figure 8: Ageing kinetics between 90 and $134^{\circ} \mathrm{C}$ for ST and MT samples. 
Table 5: Parameters of MAJ equation of the different materials.

\begin{tabular}{llllll}
\hline Material & $\mathrm{Q}(\mathrm{kJ} / \mathrm{mol})$ & $\mathrm{n}$ & $\mathrm{b}_{0}$ & $\mathrm{~V}_{\max }$ & $\mathrm{V}_{0}$ \\
& & & & & \\
\hline ST & 98.6 & 0.93 & $8.17 \bullet 10^{11}$ & 0.78 & 0 \\
MT & 112.0 & 1.78 & $7.49 \bullet 10^{12}$ & 0.79 & 0.05 \\
\hline
\end{tabular}

\section{DISCUSSION}

\subsection{FAtigue LifETIME WITHOUt THE EFFECT OF AGING}

The Equation (1) can be used to estimate the lifetime of three materials under the wet and cyclic loading conditions encountered during mastication without the effect of aging. The relevant parameters are summarized in Table 4. Meanwhile, it was assumed in this study that the failure mechanism occurred under wet condition at a lower, maximum applied load (150MPa) and a conservative mastication frequency of 1400 cycles/day[50] in vivo situation to calculate the fatigue lifetime diagrams (Fig.9). The fatigue lifetime without the effect of $\mathrm{K}_{\mathrm{I} 0}$ of ST and MT is much longer than 20 years at a maximum applied stress of $150 \mathrm{MPa}$ which is consistent with previous studies[1, 21], but the fatigue lifetime of TT is only about 10 years. The results may be determined by their mechanical properties and their SCG curve. The ST and MT samples have higher flexural strength than TT samples and this is consistent with previous studies[51]. Moreover, the ST sample and the MT sample were higher crack growth initial threshold than the TT sample under different loading conditions (whether static loading under air or cyclic loading in a saliva environment), which may be due to the different yttria content in three materials[18] (see Fig.2 and Fig.6). Comparing the fatigue lifetime of ST and MT samples under different maximum applied stresses, it can be found that MT exhibits a longer lifetime than ST in high applied stress regions, but the opposite trend occurs in low applied stress regions. This is due to the following reasons: 1. MT has a higher flexural strength due to the doping of a small amount of alumina (Fig. 3), but the irregular segregation of alumina in the zirconia grain boundary may result in a decrease in its strength reliability (As shown in Fig. 4(a) that the Weibull modulus of MT is the lowest). 2. Although the ST and MT samples have the same initial threshold for crack propagation under cyclic fatigue in the saliva environment, the ST sample has twice the stress corrosion coefficient of the MT sample (see Fig. 6 and Table 4).

- ST cal from SCG curves

$\star$ MT cal from scg curves

- TT from scg curves $\square$ ST cal from Weibull distributions

$\Delta$ MT cal from Weibull distributions

○ TT from Weibull distributions

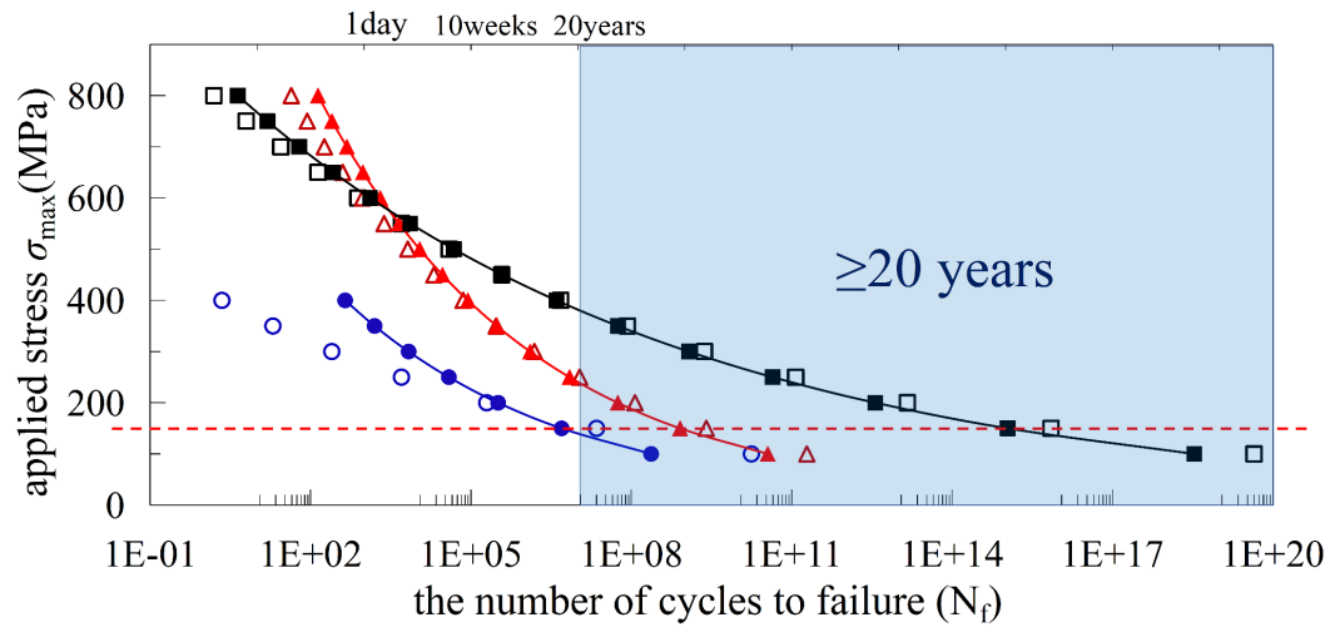

Figure 9: Fatigue lifetime diagrams calculated from Weibull distributions and subcritical crack growth (SCG) curves without the effect of aging and without the effect of $\mathrm{K}_{\mathrm{I} 0}$. 


\subsection{AGING LIFETIME}

We evaluated the aging lifetime of the three materials according to the above method. TT did not suffer from aging in the existing procedure because it has a higher yttria content than the ST and MT samples. According to the aging kinetic parameters in Table 5, the aging lifetime diagram of ST and MT are obtained in Fig 10. It has been found out from previous research results that the mechanical properties of the zirconia material will be seriously affected, when the monoclinic phase content reaches 50\% during aging[52]. Therefore, without considering the various surface treatments of three materials in clinical situations, we estimate that the aging lifetime at $37^{\circ} \mathrm{C}$ refers to the corresponding aging time when the monoclinic zirconia phase content reaches $50 \%$ during aging process at $37^{\circ} \mathrm{C}$. Here it was found that the ST sample has a aging lifetime of about 6 years at body temperature, while the MT sample can last up to nearly 100 years at $37^{\circ} \mathrm{C}$. This is consistent with the presence of small amount of alumina in MT samples [49]. When alumina is segregated at the zirconia grain boundary, the alumina can stabilize the oxygen vacancies [53-55]. The aging behaviour of zirconia is based on the annihilation process of oxygen vacancies [55]. On the basis of this, the MT samples which have a small amount of alumina showed more excellent aging resistance than the ST sample.

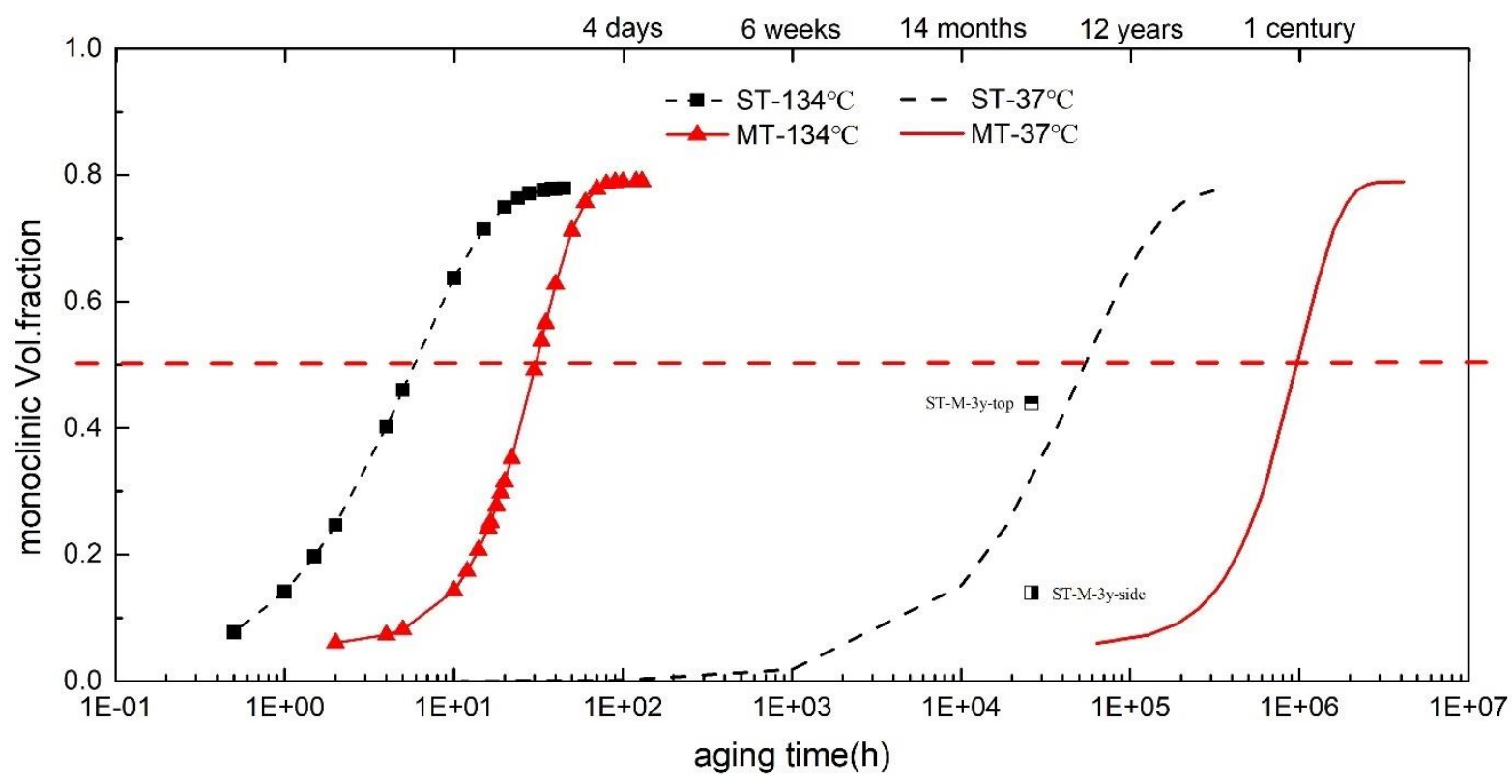

Figure 10: Ageing kinetics at 90 and $134^{\circ} \mathrm{C}$ for ST and MT samples.[52]

\subsection{LIFETIME ASSESSMENT FOR ZIRCONIA MATERIALS}

Combined with the results of fatigue lifetime and aging lifetime, the focused parameters for the three different zirconia materials in evaluating the lifetime of the human body are also different. ST zirconia ceramics should mainly consider the influence of aging process after comparing cycle fatigue lifetime and aging lifetime, and it is estimated that the service lifetime is about 6 years. Since the TT sample was resistant to aging (in the conditions of this study), the effect of cyclic fatigue was mainly considered, and the service lifetime of the material was estimated to be about 10 years. The MT material takes into account the effects of both, and it is found that the service lifetime of the material should be much longer than 20 years.

In addition, two zirconia restorations were collected after in-vivo use. And it is pointed out here that they are different from the experimental samples in that there are some surface treatments such as sandblasting and glazing. One is the ST zirconia crown bridge which has a partial shedding phenomenon in the top area after more than 3 years use (20 years old male patient). The other is $3 \mathrm{Y}$ TZP zirconia posterior crown that broke after being used more than two years (40 years old female patient). The occlusal top and sides of the two samples were characterized by XRD (Fig.11). It was found that the occlusal top exhibited more monoclinic phases than the sides, which proved to be a 
fact that the aging kinetics could be faster on loaded zones, and this led to accelerating the failure of the zirconia sample. Meanwhile, comparing Fig.10, the monoclinic phase content of the side unloaded area is less than the calculated value $(0.32)$ at $37^{\circ} \mathrm{C}$, and the monoclinic phase content of the top loaded area is greater than the calculated value after the ST zirconia was implanted in a 20 years old male patient for 3 years. The results had the following reasons: 1 . The presence of surface glaze on the side unloaded area delayed the aging process, resulting in their monoclinic phase content was less than the calculated value at $37^{\circ} \mathrm{C}[51,56] .2$. The cyclic fatigue of the top area caused the surface glaze to fall off quickly during long-term chewing to accelerate the aging of the sample surface. At the same time, the cyclic fatigue and aging processes of the top interact with each other and accelerate each other. Eventually, the top zones has more monoclinic phase content than side zones due to the acceleration of aging and the phase transformation toughening upon fracture, in turn resulting in accelerated failure of the products. Therefore, the service lifetime evaluation of dental zirconia in the oral environment should be comprehensively evaluated cycling fatigue and aging kinetics, and the mixed tests that combine aging and fatigue on the same specimens at the same time preferably should be devised to more accurately study the service lifetime of dental zirconia ceramics.
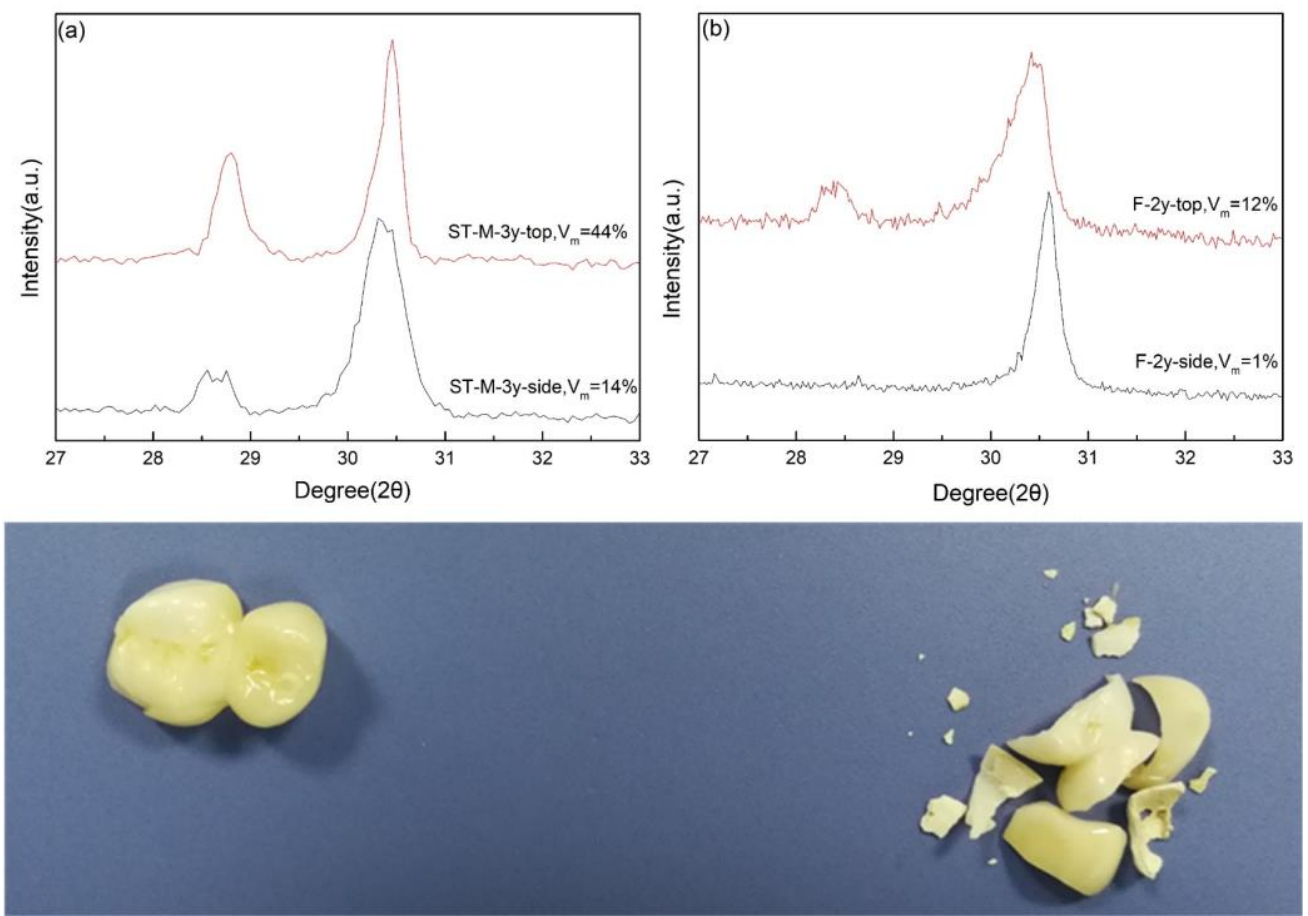

Figure 11: XRD patterns and photo of collected dental zirconia restorations. on the left is the ST zirconia product after 3 years of use by a 20 years old male patient; On the right is the zirconia product used by a 40 years old female patient for more than 2 years. 


\section{CONCLUSION}

3 mol\%-yttria stabilized zirconia ST and MT samples have higher initial mechanical strength and higher initial crack growth threshold than $5 \mathrm{~mol} \%$-yttria stabilized zirconia TT samples. The $\mathrm{K}_{\mathrm{I} 0}$ of the ST and MT samples calculated in the hardness test (static conditions in air) fluctuate between 3.26 and 3.9 MPa.m ${ }^{1 / 2}$, and the TT samples is around 2.67 MPa. $\mathrm{m}^{1 / 2}$. The $\mathrm{K}_{\mathrm{I}, \text { max }}$ calculated in the cyclic fatigue test under the saliva environment for ST and MT samples are higher than $2.4 \mathrm{MPa} \cdot \mathrm{m}^{1 / 2}$, and the TT sample are higher than $1.5 \mathrm{MPa} \cdot \mathrm{m}^{1 / 2}$. They results in that a cycle fatigue lifetime of ST and MT samples is much longer than 20 years under human conditions without considering the effects of aging, while the cyclic fatigue lifetime of TT is about 10 years. For aging kinetics, TT did not undergo aging behaviour in existing aging procedures, while ST and MT suffered varying degrees of aging. The MT has a stronger aging resistance than the ST samples due to the doping of a small amount of alumina, and the activation energies of the two are 112 and $98.6 \mathrm{~kJ} / \mathrm{mol}$, respectively. Finally, the service lifetime of the ST samples in the human body was shortened to about 6 years in consideration of aging, and the service lifetime of TT samples in the human body was evaluated to be about 10 years in consideration of cyclic fatigue. The service lifetime of MT in the human body are estimated to be much longer than 20 years due to its excellent aging resistance and mechanical properties. Therefore, we recommend that TT materials can be used for anterior teeth restoration to ensure a longer service lifetime; when ST materials are used as dental restorative materials, they should be regularly checked for the integrity of their glazes; MT material can be used as a prosthesis material for the posterior teeth.

In fact, the service conditions of zirconia dental ceramics in the human oral environment are very complicated. For example, the failure behaviour of the collected human dental zirconia ceramics is caused by the interaction of cyclic fatigue and aging. This provides us with a deeper research topic in the future, how to accurately monitor and predict the service lifetime under the interaction between cyclic fatigue and aging in vitro.

\section{DECLARATION OF INTERESTS}

The authors declare that they have no known competing financial interests or personal relationships that could have appeared to influence the work reported in this paper.

\section{ACKNOWLEDGEMENTS}

This work is supported by Northwestern Polytechnical University(Grant No. G2018KY0303) and Fundamental Research Funds for the Central Universities (Grant No. 3102017JC01003) of China.

\section{REFERENCES}

[1] A.R. Studart, F. Filser, P. Kocher, L.J. Gauckler, In vitro lifetime of dental ceramics under cyclic loading in water, Biomaterials 28(17) (2007) 2695-2705.

[2] I. Denry, J.R. Kelly, State of the art of zirconia for dental applications, Dental Materials 24(3) (2008) 299-307.

[3] E. Willems, F. Zhang, B. Van Meerbeek, J. Vleugels, Iron oxide colouring of highly-translucent 3Y-TZP ceramics for dental restorations, Journal of the European Ceramic Society 39(2) (2019) 499507.

[4] S.S.M.P. Aung, T. Takagaki, S.K. Lyann, M. Ikeda, M. Inokoshi, A. Sadr, T. Nikaido, J. Tagami, Effects of alumina-blasting pressure on the bonding to super/ultra-translucent zirconia, Dental Materials 35(5) (2019) 730-739. 
[5] M. Inokoshi, H. Shimizu, K. Nozaki, T. Takagaki, K. Yoshihara, N. Nagaoka, F. Zhang, J. Vleugels, B. Van Meerbeek, S. Minakuchi, Crystallographic and morphological analysis of sandblasted highly translucent dental zirconia, Dental Materials 34(3) (2018) 508-518.

[6] E. Camposilvan, F.G. Marro, A. Mestra, M. Anglada, Enhanced reliability of yttria-stabilized zirconia for dental applications, Acta Biomaterialia 17 (2015) 36-46.

[7] T. Miyazaki, T. Nakamura, H. Matsumura, S. Ban, T. Kobayashi, Current status of zirconia restoration, Journal of Prosthodontic Research 57(4) (2013) 236-261.

[8] J. Chevalier, L. Gremillard, A.V. Virkar, D.R. Clarke, The Tetragonal-Monoclinic Transformation in Zirconia: Lessons Learned and Future Trends, Journal of the American Ceramic Society 92(9) (2009) 1901-1920.

[9] A. Scarano, M. Stoppaccioli, T. Casolino, Zirconia crowns cemented on titanium bars using CAD/CAM: a five-year follow-up prospective clinical study of 9 patients, BMC Oral Health 19(1) (2019) 286.

[10] M. Inokoshi, F. Zhang, J. De Munck, S. Minakuchi, I. Naert, J. Vleugels, B. Van Meerbeek, K. Vanmeensel, Influence of sintering conditions on low-temperature degradation of dental zirconia, Dental Materials 30(6) (2014) 669-678.

[11] J.G. Wittneben, J. Gavric, I. Sailer, D. Buser, D. Wismeijer, Clinical and esthetic outcomes of two different prosthetic workflows for implant-supported all-ceramic single crowns-3 year results of a randomized multicenter clinical trail, Clin. Oral Implant. Res. 11.

[12] X. Niu, N. Rahbar, S. Farias, W. Soboyejo, Bio-inspired design of dental multilayers: Experiments and model, Journal of the Mechanical Behavior of Biomedical Materials 2(6) (2009) 596-602.

[13] B.T. Rafferty, M.N. Janal, R.A. Zavanelli, N.R.F.A. Silva, E.D. Rekow, V.P. Thompson, P.G. Coelho, Design features of a three-dimensional molar crown and related maximum principal stress. A finite element model study, Dental Materials 26(2) (2010) 156-163.

[14] M. Huang, N. Rahbar, R. Wang, V. Thompson, D. Rekow, W.O. Soboyejo, Bioinspired design of dental multilayers, Materials Science and Engineering: A 464(1) (2007) 315-320.

[15] J. Tinschert, K.A. Schulze, G. Natt, P. Latzke, N. Heussen, H. Spiekermann, Clinical behavior of zirconia-based fixed partial dentures made of DC-Zirkon: 3-year results, The International journal of prosthodontics 21(3) (2008) 217-22.

[16] M.K. Molin, S.L. Karlsson, Five-year clinical prospective evaluation of zirconia-based Denzir 3-unit FPDs, The International journal of prosthodontics 21(3) (2008) 223-7.

[17] J. Chevalier, C. Olagnon, G. Fantozzi, Subcritical Crack Propagation in 3Y-TZP Ceramics: Static and Cyclic Fatigue, Journal of the American Ceramic Society 82(11) (1999) 3129-3138.

[18] F. Zhang, H. Reveron, B.C. Spies, B. Van Meerbeek, J. Chevalier, Trade-off between fracture resistance and translucency of zirconia and lithium-disilicate glass ceramics for monolithic restorations, Acta Biomaterialia 91 (2019) 24-34.

[19] Y. Zhang, I. Sailer, B.R. Lawn, Fatigue of dental ceramics, Journal of Dentistry 41(12) (2013) $1135-1147$.

[20] S.M. Salazar Marocho, A.R. Studart, M.A. Bottino, A.D. Bona, Mechanical strength and subcritical crack growth under wet cyclic loading of glass-infiltrated dental ceramics, Dental Materials 26(5) (2010) 483-490.

[21] M. Wendler, R. Belli, D. Valladares, A. Petschelt, U. Lohbauer, Chairside CAD/CAM materials. Part 3: Cyclic fatigue parameters and lifetime predictions, Dental Materials 34(6) (2018) 910-921. 
[22] J.R. Kelly, P.F. Cesar, S.S. Scherrer, A. Della Bona, R. van Noort, M. Tholey, A. Vichi, U. Lohbauer, ADM guidance-ceramics: Fatigue principles and testing, Dental Materials 33(11) (2017) 1192-1204.

[23] J. Chevalier, What future for zirconia as a biomaterial?, Biomaterials 27(4) (2006) 535-543.

[24] H. Schubert, F. Frey, Stability of Y-TZP during hydrothermal treatment: neutron experiments and stability considerations, Journal of the European Ceramic Society 25(9) (2005) 1597-1602.

[25] L. Gremillard, L. Martin, L. Zych, E. Crosnier, J. Chevalier, A. Charbouillot, P. Sainsot, J. Espinouse, J.L. Aurelle, Combining ageing and wear to assess the durability of zirconia-based ceramic heads for total hip arthroplasty, Acta Biomaterialia 9(7) (2013) 7545-7555.

[26] J. Chevalier, S. Deville, E. Münch, R. Jullian, F. Lair, Critical effect of cubic phase on aging in $3 \mathrm{~mol} \%$ yttria-stabilized zirconia ceramics for hip replacement prosthesis, Biomaterials 25(24) (2004) $5539-5545$.

[27] C. Wei, L. Gremillard, Towards the prediction of hydrothermal ageing of 3Y-TZP bioceramics from processing parameters, Acta Materialia 144 (2018) 245-256.

[28] C. Wei, L. Gremillard, The influence of stresses on ageing kinetics of 3Y-and 4Y-stabilized zirconia, Journal of the European Ceramic Society 38(2) (2018) 753-760.

[29] C. Wei, L. Gremillard, Surface treatment methods for mitigation of hydrothermal ageing of zirconia, Journal of the European Ceramic Society 39(14) (2019) 4322-4329.

[30] S. Deville, J. Chevalier, L. Gremillard, Influence of surface finish and residual stresses on the ageing sensitivity of biomedical grade zirconia, Biomaterials 27(10) (2006) 2186-2192.

[31] S. Ramesh, K.Y. Sara Lee, C.Y. Tan, A review on the hydrothermal ageing behaviour of Y-TZP ceramics, Ceramics International 44(17) (2018) 20620-20634.

[32] M. Inokoshi, K. Vanmeensel, F. Zhang, J. De Munck, G. Eliades, S. Minakuchi, I. Naert, B. Van Meerbeek, J. Vleugels, Aging resistance of surface-treated dental zirconia, Dental Materials 31(2) (2015) 182-194.

[33] L. Gremillard, C. Wei, J. Chevalier, K. Hans, T. Oberbach, A fast, stepwise procedure to assess time-temperature equivalence for hydrothermal ageing of zirconia-based materials, Journal of the European Ceramic Society 38(1) (2018) 181-186.

[34] L.M. Miragaya, R.B. Guimarães, R.Othávio d.A.e. Souza, G.d. Santos Botelho, J.G. Antunes Guimarães, E.M. da Silva, Effect of intra-oral aging on $\mathrm{t} \rightarrow \mathrm{m}$ phase transformation, microstructure, and mechanical properties of Y-TZP dental ceramics, Journal of the Mechanical Behavior of Biomedical Materials 72 (2017) 14-21.

[35] P. Kohorst, L. Borchers, J. Strempel, M. Stiesch, T. Hassel, F.-W. Bach, C. Hübsch, Lowtemperature degradation of different zirconia ceramics for dental applications, Acta Biomaterialia 8(3) (2012) 1213-1220.

[36] J. Chevalier, C. Olagnon, G. Fantozzi, Study of the residual stress field around Vickers indentations in a 3Y-TZP, J. Mater. Sci. 31 (1996) 2711-2717.

[37] M.I. MENDELSON, Average Grain Size in Polycrystalline Ceramics, Journal of the American Ceramic Society 52(8) (1969) 443-446.

[38] F.F. Lange, D.B. Marshall, J.R. Porter, Controlling microstructures through phase partitioning from metastable precursors: The ZrO2-Y2O3 system, 1988.

[39] H.G. Scott, Phase relationships in the zirconia-yttria system, Journal of Materials Science 10(9) (1975) 1527-1535. 
[40] H.G. Scott, Phase relationships in the yttria-rich part of the yttria-zirconia system, Journal of Materials Science 12(2) (1977) 311-316.

[41] G.R. ANSTIS, P. CHANTIKUL, B.R. LAWN, D.B. MARSHALL, A Critical Evaluation of Indentation Techniques for Measuring Fracture Toughness: I, Direct Crack Measurements, Journal of the American Ceramic Society 64(9) (1981) 533-538.

[42] N. Garmendia, S. Grandjean, J. Chevalier, L.A. Diaz, R. Torrecillas, I. Obieta, Zirconiamultiwall carbon nanotubes dense nano-composites with an unusual balance between crack and ageing resistance, Journal of the European Ceramic Society 31(6) (2011) 1009-1014.

[43] A.R. Studart, F. Filser, P. Kocher, L.J. Gauckler, Fatigue of zirconia under cyclic loading in water and its implications for the design of dental bridges, Dental Materials 23(1) (2007) 106-114.

[44] D. Munz, T. Fett, Ceramics: Mechanical properties, failure behaviour, materials selection, Annales De Chimie Science Des Matériaux 25 (1999) 75.

[45] A.R. Studart, F. Filser, P. Kocher, H. Lüthy, L.J. Gauckler, Cyclic fatigue in water of veneerframework composites for all-ceramic dental bridges, Dental Materials 23(2) (2007) 177-185.

[46] R. Schmitt, T. Fett, D. Munz, CYCLIC FATIGUE OF ZIRCONIA, Fatigue \& Fracture of Engineering Materials \& Structures 19(12) (1996) 1411-1420.

[47] H. Toraya, M. Yoshimura, S. Somiya, Calibration Curve for Quantitative Analysis of the Monoclinic-Tetragonal ZrO2 System by X-Ray Diffraction, Journal of the American Ceramic Society 67(6) (1984) C-119-C-121.

[48] J. Chevalier, B. Cales, J.M. Drouin, Low-Temperature Aging of Y-TZP Ceramics, Journal of the American Ceramic Society 82(8) (1999) 2150-2154.

[49] F. Zhang, M. Inokoshi, K. Vanmeensel, B. Van Meerbeek, I. Naert, J. Vleugels, Lifetime estimation of zirconia ceramics by linear ageing kinetics, Acta Materialia 92 (2015) 290-298.

[50] J.R. Kelly, CERAMICS IN RESTORATIVE AND PROSTHETIC DENTISTRY, Annual Review of Materials Science 27(1) (1997) 443-468.

[51] E. Camposilvan, R. Leone, L. Gremillard, R. Sorrentino, F. Zarone, M. Ferrari, J. Chevalier, Aging resistance, mechanical properties and translucency of different yttria-stabilized zirconia ceramics for monolithic dental crown applications, Dental Materials 34(6) (2018) 879-890.

[52] G.K.R. Pereira, A.B. Venturini, T. Silvestri, K.S. Dapieve, A.F. Montagner, F.Z.M. Soares, L.F. Valandro, Low-temperature degradation of Y-TZP ceramics: A systematic review and meta-analysis, Journal of the Mechanical Behavior of Biomedical Materials 55 (2016) 151-163.

[53] X. Guo, R. Waser, Electrical properties of the grain boundaries of oxygen ion conductors: Acceptor-doped zirconia and ceria, Progress in Materials Science 51(2) (2006) 151-210.

[54] A. Samodurova, A. Kocjan, M.V. Swain, T. Kosmač, The combined effect of alumina and silica co-doping on the ageing resistance of 3Y-TZP bioceramics, Acta Biomaterialia 11 (2015) 477-487.

[55] F. Zhang, M. Batuk, J. Hadermann, G. Manfredi, A. Mariën, K. Vanmeensel, M. Inokoshi, B. Van Meerbeek, I. Naert, J. Vleugels, Effect of cation dopant radius on the hydrothermal stability of tetragonal zirconia: Grain boundary segregation and oxygen vacancy annihilation, Acta Materialia 106 (2016) 48-58.

[56] I. Sailer, A. Feher, F. Filser, L.J. Gauckler, H. Luthy, C.H. Hammerle, Five-year clinical results of zirconia frameworks for posterior fixed partial dentures, The International journal of prosthodontics 20(4) (2007) 383-8. 